07.2

\title{
Моделирование реакции низкобарьерного диода Мотта на воздействие тяжелых заряженных частиц космического пространства
}

\author{
(C) А.С. Пузанов ${ }^{1}$, В.В. Бибикова ${ }^{1}$, И.Ю. Забавичев ${ }^{1}$, Е.С. Оболенская ${ }^{1}$, Е.А. Тарасова ${ }^{1}$, \\ Н.В. Востоков ${ }^{2}$, С.В. Оболенский ${ }^{1, \uparrow}$ \\ ${ }^{1}$ Нижегородский государственный университет им. Н.И. Лобачевского, Нижний Новгород, Россия \\ ${ }^{2}$ Институт фозики микроструктур РАН, Афонино, Нижегородская обл., Россия \\ IE-mail: obolensk@rf.unn.ru
}

Поступило в Редакцию 2 ноября 2020г.

В окончательной редакции 11 декабря 2020 г.

Принято к публикации 16 декабря 2020г.

\begin{abstract}
Проведен теоретический анализ переходных ионизационных процессов, протекающих в низкобарьерном GaAs-диоде Мотта при воздействии тяжелых заряженных частиц космического пространства и имитирующих их импульсов лазерного излучения. Реакция диода на воздействие иона $\mathrm{As}^{+}$с энергией $200 \mathrm{MeV}$, соответствующей линейной передаче энергии $26 \mathrm{MeV} \cdot \mathrm{cm}^{2} / \mathrm{mg}$, сопоставляется с реакцией на действие импульсов оптического излучения различной длительности $(10-1000 \mathrm{fs})$ с энергией квантов, превышающей ширину запрещенной зоны GaAs.
\end{abstract}

Ключевые слова: диод Мотта, тяжелые заряженные частицы космического пространства, фемтосекундный лазер.

DOI: 10.21883/PJTF.2021.06.50761.18607

Развитие перспективных систем для обеспечения быстродействующей связи, в частности, космического базирования [1] требует разработки приемников и передатчиков диапазона частот $0.1-1 \mathrm{THz}$, стойких к воздействию тяжелых заряженных частиц (ТЗЧ) космического пространства. Испытания работоспособности полупроводниковых приборов при воздействии ТЗЧ приходится проводить на ускорителях частиц, что является очень трудоемкой и дорогостоящей процедурой [2]. Поэтому интерес представляет развитие имитационных методов оценки реакции изделий микро- и наноэлектроники на воздействие ТЗЧ космического пространства при помощи пикосекундных $(1-600 \mathrm{ps})$ и фемтосекундных (10-1000 fs) лазеров оптического диапазона [3]. Физическая обоснованность таких методов заключается в способности генерации в локальном объеме полупроводника неравновесных носителей заряда, что свойственно и ТЗЧ.

Несмотря на то что при воздействии лазерного излучения и ТЗЧ профили распределения неравновесных носителей заряда существенно различаются, в большинстве полупроводниковых приборов за счет процессов диффузии к началу формирования электрической реакции низкочастотных структур (через времена порядка 100 ps) различия в ионизационных токах практически исчезают. Однако эти условия не выполняются для диодов с малыми (менее $100 \mathrm{~nm}$ ) длинами активных областей, важную роль в которых играют „горячие“ носители заряда. Оценки показывают, что ТЗЧ пролетает такие структуры за времена $1-100$ ps, а электрическая реакция формируется в течение 10-100 fs после воздействия
ТЗЧ. Поскольку скорость горячих электронов и дырок зависит от их энергии нелинейно, форма импульса тока становится зависящей от длины активной области полупроводникового прибора, а также от направления движения ТЗЧ. В настоящей работе проведено сравнение действия ТЗЧ и фемтосекундного лазерного импульса с различной длительностью, интенсивностью и энергией квантов на диод с длиной активной области $100 \mathrm{~nm}$.

Одним из перспективных приборов для аппаратуры миллиметрового диапазона длин волн является неохлаждаемый GaAs-диод Мотта с пониженной эффективной высотой потенциального барьера на границе металл-полупроводник. Понижение эффективной высоты барьера достигается за счет изотипного $\delta$-легирования полупроводникового $i$-слоя на расстоянии нескольких нанометров от металла [4]. В результате в полупроводнике формируется потенциальный рельеф с туннельно-прозрачным барьером на границе с металлом, что уменьшает эффективную высоту барьера диода до значений, позволяющих не использовать постоянное смещение при детектировании. Это упрощает конструкцию приемника, приводит к снижению уровня шумов, позволяет уменьшить необходимый уровень мощности гетеродина [5], увеличивает эффективность $\mathrm{RF}-\mathrm{DC}$-преобразования [6]. Однако малые геометрические размеры элемента, реализуемые с целью достижения высокочастотных свойств, могут обеспечить высокую паразитную чувствительность к переходным ионизационным процессам, протекающим в полупроводниковых структурах при воздействии ТЗЧ. В случае использования такого прибора в цифровых системах связи 
Таблица 1. Расчетные времена пролета (в fs) диодов с разными длинами активной области для различных стартовых энергий электронов, отсчитываемых от дна зоны проводимости (вброс электрона по кратчайшему направлению к аноду, электрическое поле ускоряло электроны с момента старта)

\begin{tabular}{|c|c|c|c|c|}
\hline \multirow{2}{*}{$\begin{array}{c}\text { Напряженность } \\
\text { ускоряющего } \\
\text { электрического } \\
\text { поля, } \mathrm{kV} / \mathrm{cm}\end{array}$} & \multirow{2}{*}{$\begin{array}{c}\text { Стартовая } \\
\text { энергия } \\
\text { элекатрона, eV }\end{array}$} & \multicolumn{3}{|c|}{ Размер активной области диода } \\
\hline & & $25 \mathrm{~nm}$ & $50 \mathrm{~nm}$ & $100 \mathrm{~nm}$ \\
\hline 5 & $\begin{array}{l}0.037 \\
0.35 \\
0.6 \\
\end{array}$ & $\begin{array}{r}160 \\
330 \\
1090 \\
\end{array}$ & $\begin{array}{r}310 \\
760 \\
2590 \\
\end{array}$ & $\begin{array}{r}570 \\
1390 \\
2240 \\
\end{array}$ \\
\hline 25 & $\begin{array}{l}0.037 \\
0.35 \\
0.6\end{array}$ & $\begin{array}{r}70 \\
160 \\
460\end{array}$ & $\begin{array}{l}120 \\
340 \\
820\end{array}$ & $\begin{array}{r}200 \\
910 \\
1490\end{array}$ \\
\hline 50 & $\begin{array}{l}0.037 \\
0.35 \\
0.6\end{array}$ & $\begin{array}{r}60 \\
120 \\
370\end{array}$ & $\begin{array}{r}90 \\
320 \\
740\end{array}$ & $\begin{array}{r}180 \\
1000 \\
1470\end{array}$ \\
\hline 100 & $\begin{array}{l}0.037 \\
0.35 \\
0.6\end{array}$ & $\begin{array}{r}40 \\
100 \\
290\end{array}$ & $\begin{array}{r}70 \\
390 \\
630\end{array}$ & $\begin{array}{r}520 \\
1100 \\
1320\end{array}$ \\
\hline
\end{tabular}

П р и м е ч а н и е. Курсивом выделены минимальные времена пролета.

Таблица 2. Значения времен релаксации импульса и энергии для стартовых энергий электрона, соответствующих табл. 1

\begin{tabular}{c|c|c|c}
\hline $\begin{array}{c}\text { Энергия электрона, } \\
\text { отсчитываемая от } \\
\begin{array}{c}\text { дна зоны } \\
\text { проводимости, eV }\end{array}\end{array}$ & $\begin{array}{c}\text { Время релаксации } \\
\text { энерии электронов } \\
\text { в GaAs, fs } \\
\text { долина }\end{array}$ & $\begin{array}{c}\text { Время релаксации } \\
\text { импульса в GaAs, fs }\end{array}$ \\
\hline 0.037 & $\Gamma$ & 1000 & 220 \\
0.35 & $L$ & 2000 & 190 \\
\end{tabular}

воздействие ТЗЧ может вызвать сбои в работе таких систем. Необходимо сравнить форму ионизационного импульса при воздействии ТЗЧ и лазерного излучения.

В качестве объекта моделирования была выбрана Al/GaAs-структура низкобарьерного диода из работы [7]: толщина слаболегированного $i$-слоя (активная область диода) составляла $100 \mathrm{~nm}$, концентрация примеси в активной области $10^{14} \mathrm{~cm}^{-3}$, концентрация примеси в подложке $5 \cdot 10^{17} \mathrm{~cm}^{-3}$, слоевая концентрация доноров в $\delta$-слое $8.8 \cdot 10^{12} \mathrm{~cm}^{-2}$. При проведении расчетов предполагалось, что площадь барьерного контакта диода составляет $10 \mu \mathrm{m}^{2}(0.5 \times 20 \mu \mathrm{m})$, а сам контакт идеальный, т.е. не влияет на процесс генерации электроннодырочных пар в полупроводнике.

При воздействии ТЗЧ диаметр ионизованной области вокруг трека иона составляет $\sim 10 \mathrm{~nm}$ [8]. Фокусировка лазерного излучения в область такого размера практически невозможна, поэтому рассматривались равномерная ионизация активной области диода и последующий сбор носителей контактами. В том случае, когда трек иона пролегает по нормали от анода к катоду, время релаксации импульса тока в первом приближении определяется временем пробега ионизованных носителей заряда так же, как и при равномерной засветке лазерным излучением. Различия в переходных ионизационных процессах будут определяться динамикой разогрева и релаксации энергии неравновесных носителей заряда в рабочей области диода. Если трек частицы расположен перпендикулярно направлению анод-катод, то при попадании ТЗЧ в область $i$-слоя реализуется квазибаллистический транспорт „горячих“ неравновесных носителей заряда к контактам прибора. Имитация такого воздействия потребует как применения лазера с иной длительностью импульса, так и дополнительного подбора длины волны излучения для обеспечения соответствующего разогрева электронно-дырочного газа.

Для моделирования воздействия тяжелых заряженных частиц и лазерного излучения на диод Мотта использовалась разработанная ранее модель на основе метода Монте-Карло [9], а также оригинальная локально-неравновесная модель переноса носителей заряда [10], в которую для учета „горячих“ радиационно-генерированных неравновесных носителей заряда были добавлены уравнения баланса энергии и импульса электронов и дырок. 


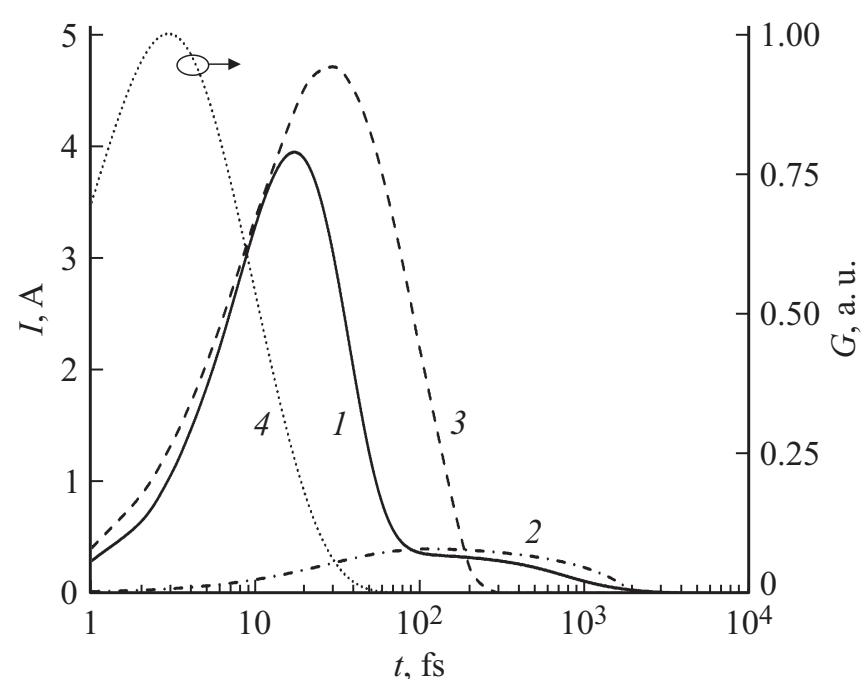

Рис. 1. Переходный ионизационный процесс в диоде Мотта при воздействии иона $\mathrm{As}^{+}$с энергией $200 \mathrm{MeV}$ и длиной трека $100 \mathrm{~nm}$ в кратчайшем направлении анод-катод (1); лазерного импульса длительностью $10 \mathrm{fs}$ без разогрева электронно-дырочного газа (2); лазерного импульса длительностью $10 \mathrm{fs}$ с разогревом электронно-дырочного газа на $0.24 \mathrm{eV}$ (3). 4 - форма лазерного импульса.

Последняя калибровалась по расчетам методом МонтеКарло и использовалась для проведения расчетов формы импульсов тока, генерируемых при облучении диодов ТЗЧ и лазерным излучением.

В табл. 1 приведены модельные результаты расчета времени пролета рабочей области диодов в приближении постоянного электрического поля в $i$-слое, являющегося ускоряющим для электронов и направленного по нормали к контактам. Эти данные позволяют оценить минимальное значение переднего фронта импульса тока, формируемого „горячими“ электронами, стартовавшими в направлении анода диода по направлению действия ускоряющей силы Кулона. Такие электроны придут к аноду быстрее более тяжелых дырок, а также электронов, которые стартуют в противоположную сторону и будут формировать спад импульса тока.

Сопоставление указанных в табл. 1 времен пролета с временами релаксации энергии и импульса (табл. 2) в объемном GaAs показывает, что для диодов с длинами 25 и $50 \mathrm{~nm}$ реализуется практически бесстолкновительное движение при напряженности электрического поля $100 \mathrm{kV} / \mathrm{cm}$, так как времена пролета (40 и $70 \mathrm{fs})$ значительно меньше времени релаксации импульса. Скорость электронов при этом превышает $9 \cdot 10^{7} \mathrm{~cm} / \mathrm{s}$. Для диода с длиной $100 \mathrm{~nm}$ за счет эффекта „убегания“ [11] peaлизуются наиболее предпочтительные условия быстрого переноса электронов в диапазоне полей $25-50 \mathrm{kV} / \mathrm{cm}$, когда время пролета сопоставимо с временем релаксации импульса, но значительно меньше времени релаксации энергии. В этом случае скорость электронов составляет $(5-7) \cdot 10^{7} \mathrm{~cm} / \mathrm{s}$. При бо́льших стартовых энергиях электрона за счет сильного рассеяния на фононах и перехода в верхние долины скорость электронов будет существенно снижаться до значений менее $10^{7} \mathrm{~cm} / \mathrm{s}$.

Число неравновесных носителей заряда в полупроводниковой структуре и, следовательно, амплитуда импульса тока определяются величинами линейной передачи энергии ТЗЧ и длиной трека иона в рабочей области диода. Рассматривалось прохождение иона $\mathrm{As}^{+}$ c энергией $200 \mathrm{MeV}$ и линейной передачей энергии $26 \mathrm{MeV} \cdot \mathrm{cm}^{2} / \mathrm{mg}$. Интенсивность лазерного излучения подбиралась таким образом, чтобы интеграл по времени от импульса тока был идентичным случаю воздействия $\mathrm{As}^{+}$.
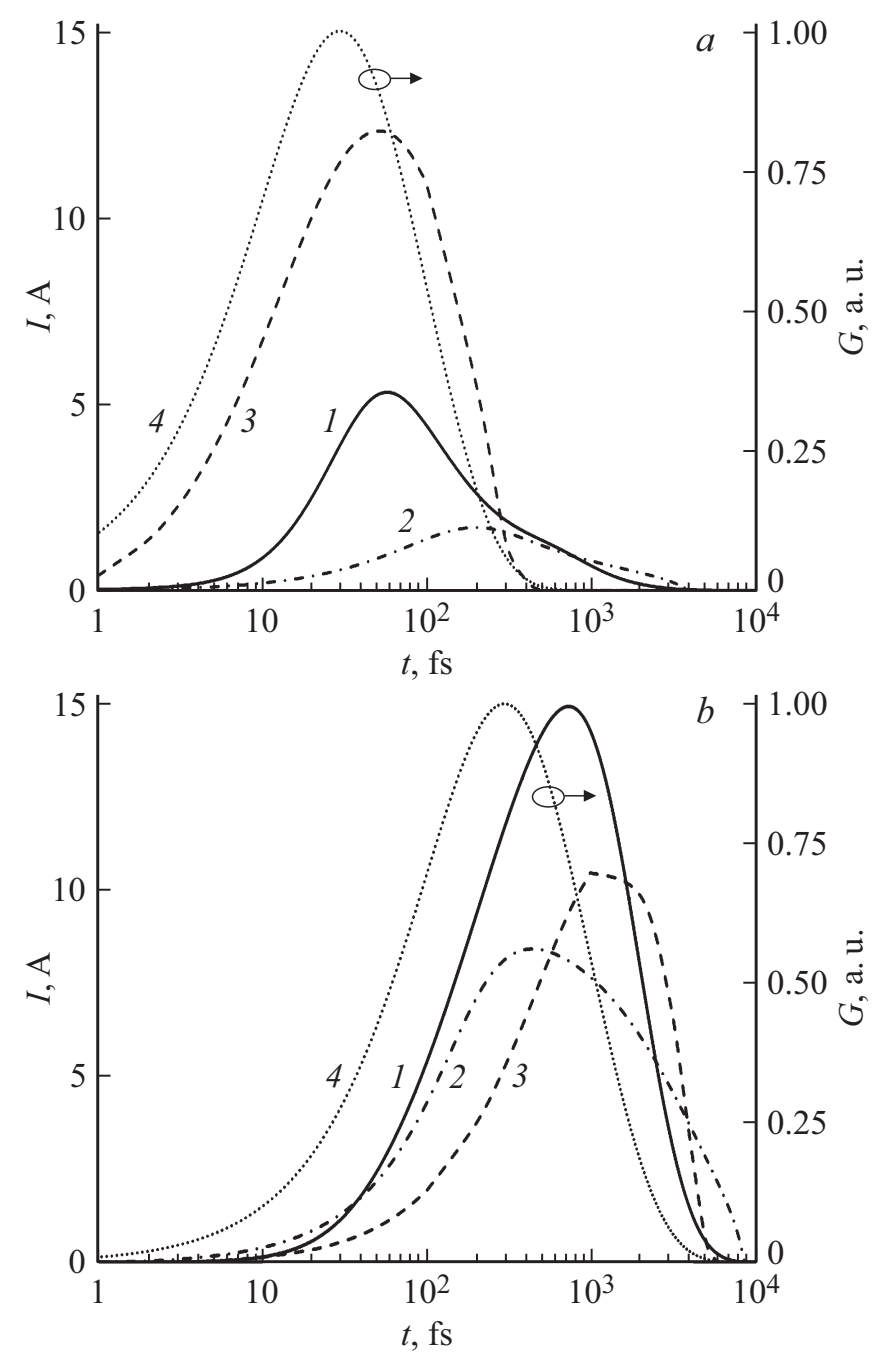

Рис. 2. Переходный ионизационный процесс в диоде Мотта при воздействии иона $\mathrm{As}^{+}$с энергией $200 \mathrm{MeV}$ и длиной трека $2(a)$ и $20 \mu \mathrm{m}(b)$ в поперечном направлении относительно линии анод-катод на расстоянии $40 \mathrm{~nm}$ от поверхности $\mathrm{Al}$ контакта $(1)$; лазерного импульса длительностью $100 \mathrm{fs}(a)$ и 1 ps $(b)$ без разогрева электронно-дырочного газа (2); лазерного импульса длительностью $100 \mathrm{fs}(a)$ и $1 \mathrm{ps}(b)$ с разогревом электронно-дырочного газа на $0.24 \mathrm{eV}(3) .4$ - форма лазерного импульса. 
Переходный ионизационный процесс в низкобарьерном диоде Мотта при облучении по нормали анод-катод представлен на рис. 1 для длины трека $100 \mathrm{~nm}$, а на рис. $2, a$ и $b$ приведены данные для длин трека 2 и $20 \mu \mathrm{m}$ соответственно в поперечном направлении относительно линии анод-катод на расстоянии $40 \mathrm{~nm}$ от поверхности Al-контакта. Увеличение энергии квантов излучения лазера до $\hbar \omega \sim 1.3 E_{g}$ позволяет учесть разогрев электронно-дырочного газа и максимально корректно описать фронт переходного ионизационного процесса. Отметим при этом различия в скорости распространения фронта ионизации, который движется со скоростью иона при воздействии ТЗЧ или со скоростью света в веществе при воздействии лазерного импульса.

Из рисунков видно, что длительность импульса тока уменьшается при разогреве электронно-дырочного газа, что связано с быстрым покиданием рабочей области диода „горячими“ носителями. При этом различия в длительности импульса относительно воздействия ТЗЧ объясняются как упомянутой выше разницей скоростей распространения возмущения, так и различием спектров „горячих“ носителей (в случае воздействия ТЗЧ он несомненно шире). Запаздывающая относительно воздействующего импульса излучения составляющая ионизационного тока формируется термализованными носителями заряда. Поэтому задний фронт импульса корректнее описывается лазером без разогрева носителей заряда.

В заключение еще раз подчеркнем, что рассмотрение влияния разогрева электронно-дырочного газа излучением и различий пространственно-временны́х распределений неравновесных носителей заряда имеет смысл только для субтерагерцевых субмикронных полупроводниковых приборов. В противном случае характеристики одиночных радиационных эффектов будут определяться исключительно локальностью энерговыделения, что накладывает особые условия на контакты устройств и измерительную оснастку при проведении испытаний на воздействие ТЗЧ и излучений, их имитирующих.

\section{Финансирование работы}

Работа выполнена в рамках базовой части государственного задания (проект № 0729-2020-0057).

\section{Конфликт интересов}

Авторы заявляют, что у них нет конфликта интересов.

\section{Список литературы}

[1] А.А. Гриценко, REDS: Телекоммуникационные устройства и системы, 7 (1), 9 (2017).

[2] А.И. Чумаков, А.А. Печенкин, А.Н. Егоров, О.Б. Маврицкий, С.В. Баранов, А.Л. Васильев, А.В. Яненко, Микроэлектроника, 37 (1), 45 (2008). [Пер. версия: 10.1007/s11180-008-1005-2].
[3] А.Н. Егоров, В.А. Телец, А.И. Чумаков, О.Б. Маврицкий, А.А. Печенкин, А.В. Яненко, Д.О. Кольцов, Электроника, 17 (5), 60 (2012).

[4] В.И. Шашкин, А.В. Мурель, Ю.Н. Дроздов, В.М. Данильцев, О.И. Хрыкин, Микроэлектроника, 26 (1), 57 (1997).

[5] В.Р. Закамов, В.И. Шашкин, Радиотехника и электроника, 56 (8), 1009 (2011). [Пер. версия: 10.1134/S1064226911060234].

[6] C.H. Petzl Lorenz, S. Hemour, K. Wu, IEEE Trans. Microware Theory Techn., 64 (7), $2146 \quad$ (2016). DOI: 10.1109/TMTT.2016.2574848

[7] S.V. Obolensky, A.V. Murel, N.V. Vostokov, V.I. Shashkin, IEEE Trans. Electron Dev., 58 (8), 2507 (2011). DOI: $10.1109 /$ TED.2011.2156410

[8] Ф.Ф. Комаров, УФН, 187 (5), 465 (2017). DOI: $10.3367 / \mathrm{UFNr} .2016 .10 .038012$

[9] Н.В. Демарина, С.В. Оболенский, ЖТФ, 72 (1), 66 (2002). [Пер. версия: 10.1134/1.1435891].

[10] А.С. Пузанов, С.В. Оболенский, В.А. Козлов, ФТП, 52 (11), 1295 (2018). DOI: 10.21883/FTP.2018.11.46586.08 [Пер. версия: 10.1134/S1063782618110209].

[11] Ю.К. Пожела, Физика быстродействующих транзисторов (Мокслас, Вильнюс, 1989), с. 57. 